Marek Zgorzelski

\title{
OROGRAPHIC BARRIER OF THE GREAT HIMALAYAS
}

\begin{abstract}
The entire geographical literature, starting with school textbooks, presents the Himalayas as a classical model of an impermeable orographic barrier, halting the masses of monsoon air and causing aridity of the Tibetan landscapes. Despite of that, however, the author, during his trips to Western and, particularly, to Central Tibet, organised exactly during the summer monsoon, always found the southern regions of these provinces flooded to a large extent with water. It is also puzzling that catastrophic floods occurring in China (connected with the high water in rivers originating in Tibet) are correlated in time with the period of the summer monsoon in the Himalayas.
\end{abstract}

Keywords: geoecology, high mountains, monsoon.

Among many natural landscape barriers (tectonic, hydrological, geochemical, etc.) orographic barriers are commonly regarded as the most important. It is they that are supposed, to a large extent, to decide about the regional or local characteristics of the climate, which differ from the global zonality of the climate, dependent on the astronomical conditions. The most commonly given example confirming this fact are the Himalayas, which supposedly stop the masses of very humid monsoon air flowing in from above the Indian Ocean; the effects of this highest orographic barrier are:

- Huge amount of rain and snow precipitation left by the monsoons on the southern slopes of the mountains, which is of great consequences for the contemporary morphogeny and for the flora.

- Great aridity of the landscapes stretching on the northern side of the Himalayas; landscapes which lie in the rain shadow of Earth's highest mountains.

While the first statement is true and confirmed by the occurrence of the so-called Rain Pole of the Earth in the region of Sikkim and Darjeeling, one can't agree fully with the second one.

Strong ascendant currents caused by the orographic barrier of the Great Himalayas (in particular in the eastern and central parts) cause a sudden rise of the humid masses of air and their displacement above the mountain range. Hence, a significant part of the monsoon moisture, in the form of snow and rain precipitation, reaches the Transhimalayas, which can form the actual climate barrier for the winter monsoon. The summer monsoon, however, reaches even much farther north. From my own observations conducted over 
a few years it follows that the summer monsoon certainly reaches the southern parts of the Tibetan Lakes (Lake Nam), and probably also farther north. The last, third and the most efficient barrier on the monsoon's route is the powerful mountain range of the Central Tibet called Suowenna-Tanggulashan. An evidence of the effect of the monsoon outside the Himalayas are large floods, time-wise related to the summer monsoon and occurring each year in the Southern Tibet as well as catastrophic floods on the territory of China, connected with the flood of the rivers with sources in the East Tibet (e.g., most recently in 2000, 2002 and 2003). To prevent them, the Chinese authorities undertook controversial decisions of building large retention reservoirs in Tibet and near its borders. These facts can't be confirmed by numerous and reliable measurement data since except for the outskirts of Tibet and the Transhimalayas (Shinghatse, Lhasa), meteorological stations have not been installed in Tibet and access to information is very limited.

The main station is located in Lhasa, at the altitude of around 4,000 metres above sea level, at the bottom of a deep valley running across the direction of the inflowing masses of humid, hot air. The results of the observations conducted there indicate that during the two summer months (July and August) the sum of the rain precipitation is equal to around $265 \mathrm{~mm}$. The maximal air temperature exceeds $20^{\circ} \mathrm{C}$ at that time, while the minimal temperature does not fall below $9^{\circ} \mathrm{C}$. The rain season in Lhasa lasts from May $(20 \mathrm{~mm})$ through September $(60 \mathrm{~mm})$. In June the precipitation reaches $70 \mathrm{~mm}$, in July, $135 \mathrm{~mm}$, and in August, $130 \mathrm{~mm}$. During the humid season (five months), when the minimal temperature does not fall below $5^{\circ} \mathrm{C}$, the rain precipitation is around 415 millimetres; while during the dry season (seven months) it is around $30 \mathrm{~mm}$, mostly in form of snow.

The occurrence of the summer monsoon precipitation beyond the Himalayas is indirectly confirmed by large differences in the rate of flow in the Indus River, whose upper segment remains within the reach of the precipitation. In the Sukkur region, during the summer season its maximum is equal to 30,000 cubic metres per second, while in the winter season its minimum reaches only 250 cubic metres per second.

Summer floods beyond the Himalayas are mentioned by the members of almost all mountain expeditions.

Monsoon reaches the Himalayas mainly through the Bengal Bay, and then moves north over the mountains and northwest above the valley of the Ganges River. Therefore it is on the southern slopes of the eastern part of the Himalayas that it starts earliest and is at the same time the most efficient. Beyond the East and Central Himalayas its range is also the largest.

The penetration of the monsoon through the High Himalayas may be explained also by the effect of the convective currents, a phenomenon taken advantage of by hang-glider pilots and balloonists in the mountains (e.g., balloon flights over Mt. Everest).

Convective currents make it possible for the birds, a.o. for cranes, to surmount the barrier of the Himalayas. The birds, flying to India and back, do 
not use the Himalayas ravines; their route runs across the highest peaks and thanks to the vertical air movements they can reach the altitude of around 9,000 metres above sea level. Thanks to the convective currents ravens reach the Southern Pass under Mt. Everest (more than 8,000 metres above sea level). The higher, steeper and more compact the mountain barrier, the stronger the convective currents occurring before it.

With respect to the directions of the monsoon attacks, the western part of the exterior arc of the Himalayas remains behind the main barrier and it is that part which eventually stops the moisture moving above the Central Himalayas. The mountain ridges Zanskar and Ladakh, situated between the Western Himalayas and Karakorum, and lower than either of them, are characterised by extremely arid climatic conditions, since they are the only ones remaining in the rain shadow of the Great Himalayas.

From the above it follows that it is not the size of an orographic barrier that decides about the halting of the factor acting on it, but - above all - the strength of this factor. A small barrier may efficiently stop a weak factor, while a large one does not necessarily block the effect of a very strong factor. In this respect, the spatial character of the barrier is of great importance. A compact, even a very tall mountain range has smaller halting capabilities with respect to mountains divided into several parts, consisting of many ridges running in different directions and divided by basins or wide valleys. These theses are confirmed also in the sphere of hydrology, although in this case the situation is more complex, since additional conditions are created by the tectonics and mountain lithology. Nonetheless, one can observe certain regularities. Large rivers (Indus, Yarlung Tsangpo, Karnali) form gorges in their course towards the south through the compact Great Himalayas, which despite of their height are not the main watershed, while the more divided mountains Altay and Hangay, half as high as the Himalayas, divide the hydrological systems of the Northern Asia and the Central Asia entirely. The full function of orographic barriers is expressed only on the local scale and it results in large differentiation of the landscapes between the slopes of warm and cold exposure.

The breakdown of the zonality of climate of a continent is therefore caused not only by the occurrence of very large orographic barriers (Himalayas, Karakorum, Pamir, Tien-Shan, Altay and Hangay) surrounding the region in question, but also a different productivity of the humid air masses flowing in from the northwest or northeast and southeast as well as of the dry air masses, flowing in from the west. The weak productivity of the climatic effect coming in from the north and carrying moisture, large distance from the source of the southern (also moist) effect, as well as aridity and a significant velocity of air masses flowing in from the west are the main causes, next to the interior orography of the region, of the extreme continentality and the desert character of the inner regions of Central Asia. Not without significance is also the interior orographic organisation of the region, in particular the multitude of orographic barriers encountered by the air masses 
flowing in from the outside. Himalayas, Transhimalayas and SuowennaTanggula-shan are situated on the way of the monsoon air, while Sayans, Hangay, Altay and the eastern ranges of Tien-Shan stand in the way of the cold and humid air masses flowing in from the north. From the west, however, only one barrier occurs: the Tien-Shan mountains, which are not a very tight barrier because of large basins and valleys dividing the mountains and running across them.

While analysing the issue of the orographic barriers one should pay attention to one more aspect of their function. Namely, in arid landscapes, where insolation and in particular one of its effects, that is, an intense evaporation, play an important role in the formation of the water balance, latitudinally situated mountain ridges fulfil an important function in the existence of the vegetation. Moisture accumulates at the base of the mountain slopes of northern exposure, situated in the shadow zone, which makes possible the existence of forest formations. Such relationship is particularly clear in the very arid Zanskar, where slopes of southern exposure are practically deprived of plants, while broadleaved forests grow at the feet of the slopes of northern exposure; the same situation can be observed in Hangay, whose slopes of southern exposure are covered by mountain steppes, while those of northern exposure, by larch forests. Hence, it is not the impulses coming from the north, but the lack of impulses that might come from the south that create in such cases an asymmetry in the forming of landscapes. 